\title{
DE LAS PRÁCTICAS MÁGICAS A LOS SORTILEGIOS AMATORIOS: LA INQUISICIÓN EN GRANADA EN EL SIGLO XVIII
}

\author{
Valérie Molero \\ ILCEA/CERHIUS. Université Stendhal-Grenoble III
}

RESUMEN: Se recogen en este artículo las prácticas más usuales de la brujería según los procesos del Santo Oficio en Granada, más activo contra este delito que los demás tribunales de la península. Los conjuros de amor puestos en obra nos introducen en un mundo mágico de creencias y tráficos sobre estos oscuros saberes en que intervienen a menudo miembros clericales y gitanas. En una época en que la presión inquisitorial se hace menos represiva, el estudio de los sortilegios amatorios nos proporciona la visión de una sociedad menesterosa, donde la pobreza estafa la miseria.

Palabras clave: Inquisición, tribunal de Granada, brujería, sortilegios amatorios, superstición, Siglo de las Luces.

\section{DES PRATIQUES DE SORCELLERIE AUX SORTILÈGES AMOUREUX: L'INQUISITION À GRENADE AU XVIII SIÈCLE}

RÉSUMÉ: Cet article présente les pratiques les plus usuelles de la sorcellerie d'après les procès du Saint-Office à Grenade, plus actif contre ce délit que les autres tribunaux de la péninsule. Les sorts amoureux mis en œuvre nous introduisent dans un monde magique de croyances et de trafics autour de ces obscurs savoirs dans lesquels interviennent souvent des membres de l'Église et des gitanes. A une époque où la pression inquisitoriale devient moins répressive, l'étude des sortilèges amoureux nous offre la vision d'une société indigente, dans laquelle la pauvreté escroque la misère.

Mots clés: Inquisition, tribunal de Grenade, sorcellerie, sortilèges amoureux, superstition, siècle des Lumières 
El estudio y análisis de las prácticas mágicas y, en particular, de los sortilegios amatorios a través de los procesos de Inquisición en el tribunal de Granada en el siglo XVIII, exige al investigador la consulta de fuentes muy variadas ya que los procesos completos de la mayoría de los tribunales han desaparecido. En el caso que nos ocupa, hay que tener muy en cuenta campos tan complejos como las alegaciones fiscales, las causas pendientes en la correspondencia entre el Consejo de la Suprema y el tribunal de distrito, las relaciones de procesos de fe y autos de fe. En la centuria citada, la jurisdicción del Santo Oficio constaba de 16 tribunales en la península y sus "islas adyacentes", Canarias y Baleares. El delito de brujería en el sentido amplio de la palabra, es decir incluyendo hechicería y todo tipo de supersticiones, sigue siendo un delito muy presente en el tribunal granadino con 156 inculpaciones sobre un total de 1.384 procesos contra supersticiosos en el territorio entre 1700 y 1820 , o sea el $11,27 \%$. Es interesante comparar esas cifras con las del conjunto de los tribunales españoles entre 1540 y 1820.

\section{Porcentaje de los procesos de magia y brujería en España}

\begin{tabular}{|c|c|c|}
\hline Fechas & Número total de procesos & Brujería, magia, superstición \\
\hline $1540-1700$ & 38.855 & 3.416 \\
\hline $1701-1746$ & 1458 & 85 \\
\hline $1700-1820$ & 9097 & 899 \\
\hline
\end{tabular}

El porcentaje de procesos contra los hechiceros en Granada es superior a la media de los tribunales en el territorio. La particularidad del tribunal radica en el hecho de que sólo se encuentran procesos contra los supersticiosos hasta 1778. No obstante, las supersticiones constituyen el tercer motivo de condena después del criptojudaísmo y del criptomahometismo. Las cifras propuestas par Teófanes Egido para los autos de fe entre 1701 et 1745 conciernen toda España y reflejan también la prioridad de la represión contra el criptojudaísmo con un total de 1.149 casos (78,80\%), seguido del mahometismo con 96 casos $(6,58 \%)$. La magia y brujería es el tercer delito en importancia con 85 casos, o sea el 5,83\% del total de las condenas durante la primera mitad del siglo XVIII. La correspondencia entre el tribunal de Granada y el Consejo de la Suprema Inquisición proporciona 232 inculpaciones de las que 19 son acusaciones múltiples. Por ejemplo: "Hereje formal y sortilegio", "Judaísmo y pacto con el demonio", "Blasfema y supersticioso", "Sospechosos de supersticiones y errores hereticales", "Apostasía y sortilegios", "Supersticiones y relapso en mahometismo". A partir del estudio de las causas pendientes, Flora García Ivars proporciona un cuadro con el número total de acusados entre los siglos XVI a XIX. Las cifras son las siguientes para la sección "hechicería" :siglo XVI (17 - 0,6\%); siglo XVII (368 - 10,3\%); siglo XVIII $(92-9,4 \%)$; siglo XIX (0). Como se observa en los porcentajes citados, hay una 
clara disminución de los procesos en los siglos XVIII y XIX. Entre las causas que intervinieron en ese descenso porcentual podríamos citar el avance de las Luces por una parte, y por otra parte los problemas económicos de la Inquisición que la obligan a frenar su actividad.

¿En qué consistían las prácticas desarrolladas por los hechiceros granadinos? Para responder a esta pregunta, una de las fuentes válidas son las alegaciones fiscales ya que a pesar de ser incompletas y remitir a menudo a las minutas del proceso completo, desafortunadamente desaparecido, ofrecen las descripciones resumidas de las prácticas supersticiosas. Además tienen la ventaja de presentar dos puntos de vista en la medida en que el proceso se iniciaba en la mayoría de los casos con una denuncia lo que permitía tener el testimonio desde fuera, esto es, desde el punto de vista de un profano que describía las operaciones sin entender todo lo que presenciaba. En una segunda fase, los inquisidores interrogaban al supuesto hechicero lo cual permite penetrar en el universo de la superstición gracias a las declaraciones de las personas iniciadas en las artes mágicas. Antes de entrar en el detalle de las actuaciones procesales, aludiremos a dos aspectos importantes que solían acompañar esos delitos: la iniciación del delincuente y la amenaza que habitualmente utilizaban para persuadir a sus víctimas.

\section{La iniciación de los hechiceros}

¿Cómo conocían los hechiceros las fórmulas y rituales que empleaban en sus prácticas supersticiosas? Las confesiones de los reos informan sobre el origen de su iniciación. Sorprendentemente, muchos sacerdotes son aficionados a este tipo de prácticas. Como saben leer y escribir, pueden utilizar varias fuentes para conocer y acordarse de cómo se realizan las operaciones mágicas.

José Giobe la Roca Francisco cuenta de él y de su cómplice Francisco Damato alias Amate, dos sacerdotes de origen italiano, "que habiéndose enseñado mutuamente el compañero y el reo varias recetas de las mencionadas en dicha causa, las han practicado por redimir su pobreza". En este caso se trata de un intercambio entre los dos curas. Francisco Damato entrega al tribunal un manuscrito que contiene cincuenta y siete cuartillas en italiano con diversas "recetas y curaciones". Esta obra es calificada por los inquisidores de "perniciosa con mistura de curaciones sortílegas, de vana observancia, impuras, dañosas a las conciencias y que podían facilitar la liviandad de las mujeres". En realidad se trataba de una compilación hecha por el propio Amate en el que consignaba las recetas que recogía durante sus viajes o que copiaba de libros de medicina o de diversos manuscritos.

Uno de los libros más importantes utilizados por los hechiceros es el Clavícula Salomonís, La Llave Menor de Salomón, que contiene los conjuros necesarios para invocar a los espíritus y obligarles a cumplir la voluntad del conjurador o exorcista según la terminología empleada en el grimorio anónimo del siglo XVII. Además, antes de poner en práctica los sortilegios, había que preparar los 
elementos necesarios para el ritual mágico. En muchos casos, era obligado cumplir determinadas operaciones de protección contra los demonios invocados para no ser víctimas de su poder.

Uno de los usuarios del popular libro de demonología es fray Pedro Sánchez, religioso recoleto de San Pedro de Alcántara. Primero cuenta que había encontrado en la librería de su convento el Clavícula Salomonís en el que se incluían numerosas recetas diabólicas, pactos, conjuros y otros sortilegios para hacerse invisible, conseguir mujeres, etc. Más adelante en el proceso, evoca a un moro como presunto dueño del libro. También habría firmado una cédula para entregar su alma al diablo y acceder al conocimiento mágico.

Un contrabandista, Pedro Felipe José Bravo, atraído por las mujeres y los tesoros, estudiaba los métodos de los que se decían hechiceros y copiaba los manuscritos y los documentos que poseían, pagando en algunas ocasiones para obtener esas informaciones.

Antonio García Remón enseña a sus compañeros de cárcel varias recetas supersticiosas, entre otras cosas para evadirse. Por lo visto, su fuente sería un asistente en el hospital de Ceuta Ilamado Victorino.

Las recetas mágicas se intercambiaban entre iniciados expertos en el tema, se vendían durante los viajes, en las cárceles, entre sacerdotes o se copiaban en los libros. La cárcel real de Granada era un lugar privilegiado para difundir los conocimientos esotéricos o las artes diabólicas con la esperanza de evadirse.

\section{La amenaza}

La amenaza asociada a la actuación supersticiosa, tenía como meta obligar a los deudores a que pagaran el trabajo de los hechiceros. Prometían obtener ciertos resultados pero en caso de incumplimiento de pago podían hechizar a sus clientes o deshacer el trabajo realizado.

Una vieja gitana, Margarita de Malla, exige el secreto sobre sus prácticas "y que si hacía lo contrario la pondría la reo de forma que no fuese más mujer en los días de su vida".

Otra gitana, Clara de Viezma, le advierte a su víctima, un religioso, que tendrá que pagarle una buena cantidad cuando haya conseguido que su hermano vuelva de las Indias "porque de lo contrario ella compondría al testigo como acostumbraba".

Francisca Romero le entrega a la futura delatora de sus actuaciones los ingredientes para seducir a un hombre. La clienta promete pagarle generosamente en caso de éxito. La reo le amenaza diciéndole "que si así no lo cumplía, entendiese que quien sabía hacer, sabía también deshacer".

Vemos en los ejemplos presentados que se trata de amenazas recurrentes e imprecisas que debían tener un impacto muy fuerte en las mentes supersticiosas de quienes acudían a las hechiceras. Dentro del conjunto de prácticas recogidas 
en los archivos, nos limitaremos a evocar los sortilegios de amor en los manuscritos inquisitoriales granadinos para conocer las fórmulas pronunciadas, los santos y demonios invocados, los ademanes específicos y las herramientas que acompañaban los rituales.

\section{La seducción y los hechizos de amor}

En los casos analizados hay muy pocos deseos de vivir una pasión amorosa. Se trata en la mayoría de los procesos de metas prosáicas como son, para los hombres, el deseo de poseer a una mujer físicamente, y para las mujeres, el deseo de encontrar a un hombre que las mantenga y ampare.

Nos enteramos gracias a las alegaciones fiscales que en el siglo XIX se creía que bastaba al hombre tocar a una mujer con aceite santo para que le siguiera.El aceite santo o santos óleos o aceite de unción era el aceite bendecido utilizado en diversas ceremonias religiosas. Se mezcla, como en muchos casos, un elemento del rito católico con las prácticas supersticiosas.

Pedro Felipe José Bravo copia en Portugal una receta que pone en práctica para seducir a una mujer:

"Tomó los testículos de una liebre cazada en el tercer viernes de mayo, hígados y sangre de paloma, lo tostó todo junto en un horno, hecho polvos lo pasó por tamiz, e introdujo en el chocolate a una portuguesa con quien tenía enemistad, y logró que esta mujer estimase al reo y aborreciese a otro amigo".

Los manuscritos ofrecen varios ejemplos del uso heterodoxo del chocolate en las prácticas mágicas relacionadas con la salud, las adivinaciones, los encantamientos, los maleficios y en todos los tipos de sortilegios amatorios.

Las oraciones de uso común en España relacionadas con la atracción amorosa o el retorno del amor perdido podían también servir contra los maridos agresivos. Es el caso de Lucía de Escalante, quien según los testimonios registrados en el tribunal de Granada, en el siglo XVIII, en el que para evitar los malos tratos de su marido, recitaba:

Con dos te miro, con tres te ato, de tu sangre bebo, el corazón te parto, que estés tan sujeto a mí, como la suela de este zapato.

Antón, Antón

ata y desata

este bobalitón. 
Según el Clavícula Salomonís, era preciso utilizar esperma humano y sangre menstrual para atraer a las mujeres. Fray Pedro Sánchez alega ante los inquisidores que se ha negado a repetir la exhortación necesaria "por ser muy horrorosa".

Para seducir a los hombres, Francisca Romero declamaba:

"Fulano yo te encomiendo

Con Señor San Antón y con la Santísima Trinidad

que no puedas parar, ni sosegar,

ni un punto estar, ni con mujer hablar,

ni cabalgar soltera, viuda, casada, ni doncella,

hasta que conmigo vengas a estar

y me digas lo que supieres

y me alargues los que pudieres

Señor San Antón con el cordón cordonazo,

Con el bastón bastonazo,

Con la campanilla, campanillazo

Y gente fuera gente fuera".

Luego daba tres golpes con el pie izquierdo. En su declaración, la mujer confiesa que no sólo usaba ese conjuro para atrer a hombres sino también para que el hijo de su clienta amara a su madre, no se interesara por otras mujeres y no gastara dinero con ellas.

Para saber si la persona deseada iba a venir y forzarla a que acudiera, Lucía Escalante ponía una lámpara encendida en el dedo del corazón diciendo las siguientes palabras:

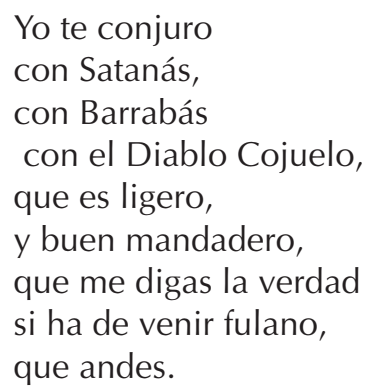

Si la lámpara se movía era señal de que la persona vendría. Esta oración debía decirse el martes o el viernes. Lucía Escalante la pone en práctica para que el pretendiente de María de Orta venga, pero su invocación no da resultado.

Dos mujeres públicas, Josefa de León y su madre, Ana de Castro, dibujaban en su rostro y su pecho al salir de su casa una cruz pronunciando: “¿dónde vas 
Pepa? A buscar venturas". Si veían pasar a hombres decían "bien vamos", si veían mujeres "mal vamos", si se cruzaban con un cura "mal aventura llevamos". Cuando salían en busca de hombres recitaban la siguiente oración:
San Antón de Paula, en Paula naciste, en Paula fuiste criado, en Lisboa muerto y sepultado, el Breviario perdiste tres pasos atrás volviste.

Esas palabras les permitía encontrar al hombre que buscaban y evitar que el marido celoso de Josefa las siguiera.

Uno de los ingredientes importantes en todo rito mágico relacionado con la atracción amorosa es la piedra imán a la cual hay múltiples alusiones en los documentos. Se suponía que esa piedra mágica, verdadera panacea del amor por medio de hechizo, le permitía a la persona que la poseía cumplir todos sus deseos.

La gitana María Narcisa de Salazar estafa a la marquesa de Diezma vendiéndole una piedra imán compuesta, es decir preparada para obtener todo lo que quisisera el que la poseía. La gitana cuenta a los inquisidores que un día de agosto de 1750, encontró a la marquesa Ilorando porque su marido la había sorprendido con don Manuel de Cañaveral, y la había amenazado insultándola. Según la gitana, la marquesa buscaba a alguien para matar a su marido y poder casarse con don Manuel. Para conseguir la famosa piedra imán, la marquesa estaba dispuesta a vender sus joyas. A pesar de tantas maniobras para conseguir estar con el amante, éste acaba abandonando a la marquesa quien decide vengarse, según el testimonio de María Narcisa, pidiendo a la gitana que le ligue, es decir, que no pueda realizar el acto carnal.

El número tres tiene una fuerte connotación simbólica vinculada a la religión católica ya que la reo le recomienda comprar tres varas de cinta encarnada, hacerle tres nudos y recitar treinta y tres credos correspondientes a los treinta y tres años de presencia de Cristo en la tierra. Según la gitana, gracias a las acciones conjuntas de la piedra imán y del conjuro, don Manuel debía de encontrarse ligado. Ligar un hombre era un hechizo corriente en varias zonas de España y hasta se creía que un pueblo entero podía llegar a ser impotente como resultado de ese peculiar maleficio.

María Manuela Contreras de Jesús, prisionera con Lucía Escalante en la cárcel real, declara que el acusado le ha enseñado a conjurar la piedra imán a fin de atraer hombres, recibir limosna y realizar todos sus deseos con la oración siguiente : 
Yo te conjuro Piedra Imán con Satanás, Con Barrabás, y María Padilla, los diablos de la pescadería, y el diablo Cojuelo, que entró en la postre y salió el primero, que todos os juntéis y en esta piedra suerte me deis.

Cuando se acababa de decir eso, bastaba con indicar a la piedra lo que se quería.

Lucía Escalante llega un día a casa de María de Orta con cinco piedras imanes. Las ditribuye a las mujeres presentes y se queda con la más grande. Les recomienda que "en los miércoles y viernes a hora de misa mayor las echasen por espacio de una hora en aguardiente junto con la plata que cada una tuviese y un maravedí de San Lázaro". La acusada les enseña una oración que les permitirá, con la ayuda de la piedra. atraer a la persona de su elección:

A mi cama me voy a acostar, a dormir, y descansar.

Por el sueño de tus ojos se me venga a los míos, para que puedas estar conmigo

la cama en que duermas, que sea de hortigas

y que te piquen dos mil savandijas, unas preñadas y otras por parir:

el sueño de tus ojos se me venga a mí:

por aquellos dolores que pasaron para parir,

pases tú por verme a mí, que no te dejen parar, ni sosegar,

hasta que conmigo vengas a estar y hablar.

Con esta exhortación les hace golpear tres veces el suelo con el pie. Una vez más vuelve la ocurrencia del número tres cuyo poder permite reforzar los conjuros. Estas prácticas basadas en el simbolismo permiten también a las prostitutas intentar fidelizar a sus clientes.

La piedra imán se puede utilizar de diversas maneras, Ilevarla consigo, como colgante, en el bolsillo, los hechiceros pueden conjurarla, los supersticiosos pueden dirigirle exhortaciones. Otros prefieren mezclarla con ingredientes para obtener una mixtura mágica.

María de Orta recurre a varias hechiceras a fin de poder encontrar a su amante sin que el marido se dé cuenta de su infidelidad. Para conseguirlo, la gitana María N. le proporciona un imán para atraer a su galán y hacer que se sienta más enamorado. Hay que precisar que el amante es religioso. El efecto debe durar entre ocho y quince días para lo cual la gitana debe volver a componer la piedra imán, lo que hará unas nueve veces más a cambio de una retribución. María de Orta desea que 
el efecto sea más duradero, que su amante aborrezca a las otras mujeres y piense que son todas feas. La gitana le pide un poco de miel blanca y aceite, con lo cual la hechicera prepara una mixtura con la piedra, destinada a espolvorear al hombre para que ame locamente a la clienta. El efecto es tan eficaz que María de Orta tiene que acudir de nuevo a la gitana para pedirle que calme los ardores de su galán.

La adivinación es otro de los trucos de los hechiceros que puede tener una doble finalidad: adivinar el futuro y atraer a las personas. Es una especialidad de las mujeres.

Francisca Romero leía las cartas diciendo:

"Yo tengo miedo y te conjuro

con Barrabás, con Satanás

y María Padilla y toda su cuadrilla,

y al Diablo Cojuelo, por ser más ligero,

le mando, impelo

porque se me diga la verdad.

Disponía luego trece cartas en derredor y las distribuía a los presentes diciendo:

a la puerta llaman, ¿quienes?

si es que manda una señora fulana

que se le ofrece,

esto la quería,

esto la traía,

esto la venía a dar,

esta es la silla donde se ha de sentar,

esto es en lo que ha de venir a parar.

Los sortilegios amatorios suelen ser en el tribunal de Granada una especialidad de las gitanas. Esas prácticas están ligadas a la estafa que consiste en robar algunos elementos de poco valor como en el caso de Isabel López, de edad de 23 años, quien en 1739 denuncia a Margarita de Malla, una vieja gitana de Granada. El marido de la joven es soldado, se encuentra a más de 200 leguas de Granada. La gitana le propone hacerle regresar. Le pide dinero y le recomienda que pronuncie:

Hijo mío de mi corazón

Tú que te fuiste, tú volverás

-dos hormigueros tengas en tus lados-

que no puedas parar

debajo de ti mil abujas tendrás

en tu cabezona mil piedras tendrás

que no te dejarán dormir.

La gitana desaparece llevándose la camisa de la mujer y el dinero, por supuesto, sin lograr nada. 


\section{El conjuro mortal}

Los hechizos relacionados con el amor o el desamor pueden Ilevar a acudir al hechicero para que practique un conjuro mortal. Este podía lograrse recitando de rodillas durante nueve días, el salmo Deus meus laudem meam netacueris con una cruz en el suelo, una estola negra alrededor del cuello y una vela amarilla delante.

Según Antonio García Remón, bastaba con elaborar una muñeca de cera profiriendo algunos conjuros, clavar alfileres y para acabar con la vida de la víctima, acuchillarle.

La estafa, resultado que siempre se obtiene con las maniobras empleadas, adopta unas formas que hacen pensar a la víctima que puede tener éxito en sus empresas. Rosa de Nagera quería deshacerse de su marido para casarse con otro. La gitana Rita de Torres acepta matarle transmitiéndole la enfermedad del carbón. Para que su amante esté enamorado de Rosa, la gitana le entrega un hueso de gato. Le pide harina, carbón, nueve pesetas, dos agujas y una mortaja, también que le traigan una escoba nueva, una aguja grande y una camisa. Confecciona un tronco con la escoba y los brazos con un junco. Rosa viste con la camisa a este muñeco que representa a su marido y le clava una aguja. La hechicera recomienda a Rosa que vaya hundiendo progresivamente la aguja durante tres días y que guarde la escoba en un baúl. Más tarde prepara una galleta con la harina, las pesetas y las agujas recitando dos oraciones. La noche anterior, la acusada había preparado dos huesos de gato negro que aseguraba haber dejado el diablo cerca de San Miguel el Alto. La gitana declara que no puede llevar la galleta porque ella está embarazada y la persona que va a entregarle los elementos mágicos al demonio debe tener tres relaciones sexuales con él. Horrorizados, Rosa se niega a presentarse a la cita con el demonio. Rita de Torres propone "sacrificarse" y se marcha con la galleta, la mortaja, la camisa, la escoba, un pañuelo y un espejo. Como era de suponer, no vuelve más. Este relato muestra hasta qué punto las supersticiones impregnan la sociedad dieciochesca, todos creyendo los relatos y las situaciones más inverosímiles. Desde este punto de vista, los manuscritos inquisitoriales nos permiten conocer un aspecto de las vivencias de la época que no pueden conocerse a través de otras vías, ya que los conocimientos se solían transmitir oralmente, siendo analfabeta la mayoría de la población.

\section{Secretos de gitanas y estafa}

Las gitanas procesadas son pobres en su mayoría, las que trabajan tienen empleos modestos como Clara de Viezma que se dedicaba a vender ropa pasando de casa en casa. La gitana declara a los inquisidores que:

no gitaneó hasta que murió su marido que hacía unos cuatro años, y que gitanear, significaba decir la buena ventura, que era que en las casas 
adonde entraba a vender prendas, decir señorita o señorito, quiere que le diga la buena ventura y si condescendían, les tomaba la mano y si era soltera la decía la reo, tía que conozco que tienes unos ojos de enamorada, perezosita por la mañana, amiga de dormir mucho, $y$ te has de casar con un Juan (o otro nombre que se la ofrecía) y otros varios embustes y enredos, todo a fin de que la diesen limosna y lo mismo hacía con los mozos solteros y casados, acomodando la relación a los estados de cada uno.

Para impresionar a su clienta, la gitana cuenta que "tiene gracia" y le pide un recipiente con agua. En él deposita tres bolitas con alfileres clavados previamente. La víctima del engaño oye a la hechicera murmurar mientras las bolitas bajan y suben en el agua. Al día siguiente, la gitana le propone hacer un conjuro mortal contra el marido. No sabemos si la propuesta fue aceptada.

Con fray Antonio de Jesús, religioso de Granada cuyo hermano está en las Indias, la gitana repite el truco del agua y de las agujas asegurando que es bruja y que tiene el poder de hacer llegar una carta de su hermano o a él mismo en carne y hueso:

puso una escudilla de agua, y dentro de ella dos alfileres punta con punta y con palabras que dijo secretas hizo subir a los alfileres nadando sobre dicha agua, y habiendo vuelto a hundirse, volvió la reo a decir las palabras y volvieron a subir dichos alfileres hasta que descubrieron las puntas fuera de la agua y después se volvieron a hundir.

Clara de Viezma confiesa a los inquisidores que el movimiento de las agujas:

se hacía naturalmente en esta forma en un palito de avena apretándolo con los dedos, se ponía en las puntas dos migajas de cera, y allí un alfiler y como estaba apretado al tiempo de desunirse, se meneaban dichos alfileres con lo que se les hacía creer, que era hechicera, y más diciéndoles, que rezasen tres credos, pero nada de ello era con pacto y sí sólo por sacar dinero.

La procesada sigue con su clase de física y más adelante de química contando a los inquisidores que al día siguiente, inventando que el hermano se había casado con una mujer rica, le propuso al religioso enseñarle una imagen de su hermano y su cuñada. Recurre al engaño del papel en el agua que describe de la manera siguiente:

puso una porcelana de agua y haciéndola sacar al testigo medio pliego de papel lo tomó la reo y dobló y poniéndoselo al testigo bajo del pie dijo la reo una palabras y le sacó el papel del pie y lo puso sobre la agua estendido, diciéndole al testigo dijese con ella estas palabras: Ya que no tengo ánimo para salir a registrar de noche dónde está mi hermano, sea traído aquí con mi cuñada y señalado en ese papel parte del caudal 
y doblones que tiene y con dichas palabras vio en dicho papel una estampa de hombre y mujer y diferentes óvalos grandes y pequeños lo que visto por el testigo quedó absorto.

Explica el truco diciendo que ha hecho el dibujo en el pliego de papel y un poco de alumbre. A continuación, aclara que la pintura con azufre tiene la particularidad de ser visible sólo en el agua y mientras el papel se mantiene húmedo.

\section{La represión inquisitorial}

Los delincuentes granadinos en su mayoría son de baja extracción social. El $88 \%$ de las mujeres hechiceras son costureras, hilanderas o lavanderas. Las penas impuestas son en algunos casos severas pero ya no se usa en el siglo XVIII la pena de hoguera contra el delito de hechicería. El tormento para obtener la confesión de los reos tampoco se suele aplicar a los supersiciosos aunque se aluda a la tortura en algunos casos.Margarita de Malla, acusada de ser sortílega embustera, salió al auto de fe siendo condenada a 6 años de destierro, a recibir 200 latigazos, reclusa un año y entregada a persona docta.

Rita de Torres escapó a una pena dura ya que fue "reconocida la reo por médico y cirujano en 28 de abril de 1747. Dijeron hallarse preñada en 5 meses, por lo que no estaba capaz de tortura, azotes, ni vergüenza pública, ni de otra...".

\section{Conclusión}

En Granada en el siglo XVIII, el estudio de los sortilegios amatorios nos proporciona una visión de la sociedad pobre y supersticiosa. Las mujeres indigentes y las gitanas embusteras representan la mayor parte de las procesadas en el tribunal granadino en el siglo de las Luces. Las reos confiesan que sus actuaciones tenían como objetivo sacar dinero a otras personas crédulas y desesperadas para socorrer su propia pobreza. Las acusaciones del Santo Oficio evocan ese aspecto múltiple del delito: "superstición, embustera y hechicera", "embustera sortílega maléfica", etc. En ese mundo paralelo en el que algunas personas intentan dominar su destino o cambiar el curso de sus vidas, las mujeres estafan a otras mujeres aprovechando sus dificultades.

En los sortilegios amatorios, los elementos empleados son la piedra imán, el conjuro a Satanás, Barrabás, el Diablo Cojuelo y María Padilla. Satanás y Barrabás - el príncipe de los demonios y el asesino que los judíos liberaron condenando a Jesucristo -, suelen estar asociados a unas invocaciones que riman. En el Quijote cuando hablando de los "malditos libros de caballerías" que le han vuelto el juicio, dice el ama de llaves de don Quijote: "Encomendados sean a Satanás y a Barrabás tales libros, que así han echado a perder el más delicado entendimiento que había en toda la Mancha". El Diablo Cojuelo introduce una con- 
notación popular ya que es el diablo más mencionado en los hechizos y es un personaje famoso de la cultura castellana del siglo XVII donde aparece en refranes, dichos, canciones y en la literatura, en particular con la obra de Luis Vélez de Guevara. En cuanto a María Padilla, las gitanas suelen invocar su nombre para las conquistas amorosas. Efectivamente, fue la favorita de Pedro I el Cruel, rey de Castilla, a quien reconoció como su único amor incluso después de muerta, a pesar de no ser su esposa legal. Puede considerarse a ese personaje del siglo XIV como el símbolo del amor triunfante.

Entre los métodos empleados, dos técnicas destacan. Una opera por transferencia, la otra, más directa y probablemente más nociva se funda en la absorción de polvos y filtros. La magia por transferencia o analógica utiliza símbolos de muerte cuando un cónyuge quiere librarse de su pareja en una sociedad en que sólo la muerte podía separar a los casados. Los elementos empleados son los huesos de difuntos o de gatos, la mortaja, etc. Una de las técnicas tradicionales consiste en representar a la víctima bajo la forma de un muñeco de cera en la que se clavan alfileres. En el sortilegio que consiste en ligar a los hombres, las cintas y los nudos que se hacen simbolizan las trabas maléficas puestas al varón. La cinta y sus nudos también evocan el vínculo que hará volver al amante o pueden servir para atraer al galán. En cuanto a la seducción, los acusados utilizan el imán como medio para transferir su poder de atracción de un hombre hacia una mujer. La magia directa actúa con la ingestión de productos añadidos a la comida o la bebida de la víctima del sortilegio. La connotación sexual es evidente: testículos de liebre, esperma humano, sangre menstrual, pero también elementos macabros como huesos de difuntos o de gatos pueden utilizarse en polvo para atraer al sexo opuesto o provocar enfermedades mortales.

Los elementos del rito católico y la alusión a Jesucristo y a los santos, en particular a San Antonio de Padua, Ilamado Antón en las oraciones, es una constante. Se usa aceite santo, cruces, estolas. Los sortilegios representan una esperanza de conseguir, desvirtuando la norma católica, un presente o un futuro mejor. En ese anhelo de encontrar soluciones a sus desdichas, los manuscritos inquisitoriales nos abren la ventana de un mundo en el que somos testigos de cómo la pobreza estafa a la miseria. 